The web art's work The Omega Myth is based in evolutionary design and its proposal is the generation of an interactive artistic site, a new kind of poetic what the audience taking part of the work as interactor. It also intends to promote the transdisciplinarity, integrating researchers from computer science, biologic sciences $\&$ arts on creation of a digital poetic. This paper shows the creative process of this work in progress that involves the development of specific programs for generation of the artwork's environments, integrates poetic artistic \& computer science, promoting reflection and generation of new software on the areas of artificial intelligence, evolutionary algorithms \& Java 2D.

Keywords: Cyber art, evolutionary design, posthuman. 


\section{Em busca de um mito sincrético total: ciberarte e vida artificial}

Edgar Silveira

FRANCO

O Mito Ômega é um trabalho de web arte inspirado pelo conceito de design evolucionário, a obra promove a transdisciplinaridade integrando pesquisadores da ciência da computação, das ciências biológicas e das artes na criação de uma poética tecnológica. O trabalho envolve a geração de um ambiente digital interativo que se inscreve dentre as investigações de arte \& vida artificial em que o público fruidor do trabalho participa também como interator. Este artigo relata o processo criativo desse work in progress que envolve a geração dos ambientes digitais que compõem a obra, incluindo o desenvolvimento de softwares nas áreas de inteligência artificial, redes neurais, algoritmos evolucionários e Java 2D.

Palavras-chave: Ciberarte, design evolucionário, pós-humano. 


\section{A busca do mito ômega: uma poética ciberartística}

Múltiplas criaturas mitológicas povoam o imaginário dos povos e culturas humanas em todas as eras. Alguns desses mitos configuram aquilo que Jung chamou de arquétipo, substrato profundo da cultura humana, que já se inseriu no cerne da espécie sendo transmitido geneticamente, como um manancial cultural inerente a toda humanidade.

Muitos arquétipos estruturam-se na forma de mitos que se assemelham profundamente, mesmo aparecendo em épocas e culturas muito distintas, como é o caso do mito grego da Sereia, a bela, sedutora e mortífera criatura dos mares, híbrido "humanimal", mixando ao corpo de mulher uma cauda de peixe. Ela tem uma "irmã" muito semelhante na cultura indígena e cabocla brasileira, a chamada Yara ou Mãe D’Água que também hipnotiza os pescadores com sua beleza e leva-os a mergulhar para a morte na água dos rios. Os seres híbridos de animal e homem, ou animal e animal formam grande parte do manancial mítico global, desde o Minotauro de Creta, passando pelo mítico Quetzalcoatl, Deus serpente emplumada da cultura ancestral Asteca, chegando finalmente a mitos modernos como o do Chupacabras e do Pé-grande, seres lendários estudados pela criptozoologia.

Criaturas transgênicas - fruto dos avanços da biogenética já são uma realidade, e o futuro talvez venha a revelar-nos um mundo de pós-humanos híbridos, tornando também verdade o design de mitos imemoriais. A tecnologia computacional tem também nos proporcionado sistemas antes inimagináveis, introduzindo a possibilidade de geração de ambientes de vida artificial, com redes neurais e algoritmos evolucionários, universos de uma nova "biologia digital", com regras preestabelecidas que permitem o desenvolvimento independente de mundos digitais, onde criaturas de vida artificial interagem, hibridizando-se, reproduzindo-se e evoluindo.

O Mito mega é um trabalho de web arte baseado no conceito de Evolutionary Design, definido por Christa Sommerer \& Laurent Mignonneau em sua obra Life Spacies: Life Spacies é baseado na idéia de design evolucionário, o que significa que o artista não cria as criaturas, mas o design dessas criaturas de- 
pende da interação dos visitantes em seu processo evolucionário" (SOMMERER, 1997) O projeto tem como objetivo principal a criação de um site onde internautas de todo o mundo são convidados a interagir com um ambiente digital composto por algarismos evolucionários, primeiro mixando seu metafórico DNA digital, obtido a partir da decodificação de seu nome digitado em um formulário, ao DNA digital de uma criatura mítica previamente gerada em computação, criando assim uma criatura singular, que posteriormente é inserida num ambiente de vida artificial e dentro dele irá se mixar a outras criaturas preexistentes em constante processo de reprodução e evolução.

A evolução das criaturas, baseada em princípios pré-programados de "seleção natural", acontece independente da intervenção dos internautas/visitantes, mas é modificada a partir do momento em que eles contribuírem com a singularidade de uma nova criatura gerada a partir de seu DNA metafórico A obra pretende unir, remetendo-nos a Couchot (2003), aquilo que ele chama de interatividade endógena - das entidades virtuais entre si, e exógena - do espectador para com o mundo digital.

A obra ciberartística utiliza-se da interação de uma maneira dinâmica e renovada, pois a chamada interatividade endógena é um atributo único dos sistemas computacionais, possui base numérica. As criaturas do ambiente evolutivo digital tornam-se atores do processo, elas possuem um comportamento específico definido pela programação e trocam mensagens entre si e com os usuários do sistema: o público interator.

O Mito Ômega, design metafórico da criatura síntese de todos os mitos do globo, será a última criatura gerada no ambiente de vida artificial, após um ano de permanência do site on-line. Depois de centenas de gerações - o design desse mito final é algo totalmente imprevisível para os criadores do projeto. O trabalho se insere em um dos novos campos da arte que integra novas tecnologias computacionais, como inteligência artificial, algoritmos genéticos, redes neurais e ambientes de vida artificial, sendo uma proposta transdisciplinar que integra à poética artística a participação efetiva de pesquisadores do campo da ciência da computação - para a geração dos progra- 
mas, da arte - para a sua concepção poética e das ciências biológicas - para auxiliar na criação dos parâmetros evolucionários das criaturas virtuais.

\section{O processo criativo do trabalho: work in progress}

A seleção dos quinze mitos que compõem o nosso projeto foi feita a partir de alguns critérios de relevância Procuramos bases que produzissem uma amostra representativa da mitologia do planeta. A opção por selecionarmos três criaturas mitológicas de cada continente foi tomada por acreditarmos que uma amostra representativa mínima dos mitos de um continente deveria envolver ao menos três criaturas, é claro que um número maior seria mais interessante, mas também precisávamos adequar a proposta ao tempo e apoio financeiro disponível para o seu desenvolvimento.

Mitos Imemoriais e Mitos Contemporâneos - Algumas culturas tradicionais do passado, com especial destaque para a Helênica e a Egípcia, são detentoras de um manancial mitológico que influenciou de forma marcante toda a cultura ocidental, produzindo alguns mitos que se tornaram arquétipos ao longo das eras. Por sua profunda influência optamos por selecionar dois mitos de cada uma dessas culturas para ressaltar sua representatividade na esfera mitológica global. Além dos mitos imemoriais de culturas ditas civilizadas, também incluímos seres mitológicos de culturas nativas de diversos povos, desde o mito indígena e caboclo da Yara, do folclore brasileiro, até deidades fundamentais de culturas tribais ancestrais da Oceania, como Tama Pua, o Deus porco-homem, e Tanemahuta, Deus das florestas. Finalmente decidimos por incluir alguns mitos mais recentes, frutos de lendas perpetradas no mundo contemporâneo, sendo eles o Pé-grande, mito da América do Norte com cerca de 200 anos passados desde os primeiros relatos sobre sua existência; e o Chupacabras, mito mais recente, com centenas de relatos provindo de países da América Latina a partir da década de 1990. Com a adoção de todos esses critérios, acreditamos ter conseguido selecionar uma amostra representativa e interessante dos mitos planetários. 
Gêneros - No estudo exploratório da mitologia global, observamos uma predominância de mitos masculinos, apesar da presença marcante das divindades femininas. Como trabalhamos com três criaturas mitológicas por continente, decidimos incluir um mito de características femininas para cada um deles. É importante ressaltar que algumas divindades míticas possuem características masculinas e femininas apesar da predominância de um dos sexos, como é o caso de Ganesh, divindade hindu que hibridiza características humanas às de um elefante; assim como Babamik, a deusa crocodilo da Oceania, que possui aspectos relacionados ao gênero masculino. Na somatória final, ficamos com dez seres míticos de características predominantemente masculinas e cinco com características predominantemente femininas.

Definidas as criaturas mitológicas que comporiam o projeto, iniciamos o estudo das interfaces e programações para transformar os mitos selecionados e pré-desenhados em entidades virtuais, baseadas em design numérico. Essa fase foi uma das mais complexas de todo o processo e envolveu pelo menos uma centena de testes visando chegar a uma solução viável para a hibridização das criaturas e produção de seus "descendentes virtuais", baseados no conceito numérico de morfagem (morph). Uma das razões por optarmos pelo uso de gráficos em duas dimensões (2D) no projeto foi a intenção de acompanhar até que ponto o traço "autoral" do artista que concebeu as criaturas iniciais permaneceria como uma marca nas criaturas geradas no ambiente evolutivo digital; observar se essa autoralidade do design continuaria vigente nas novas criaturas e por quantas gerações ela duraria. Esse tipo de análise torna-se mais complexa nas criações numéricas em três dimensões, já que para chegar a imagens com uma autoralidade premente em imagens 3D é necessário um bom conhecimento da técnica e também softwares muito evoluídos e dispendiosos, coisa de que não dispúnhamos.

Finalmente a idéia de todo o trabalho incluía sua disponibilização para o público na rede Internet era necessário investigarmos uma linguagem de programação que fosse interessante tanto no aspecto da geração das imagens, como de sua inte- 
gração com a linguagem HTML (linguagem da web) e com o banco de dados que suportaria o ambiente gerativo de algoritmos genéticos, em linguagem PHP. A opção mais evidente foi pela linguagem de programação JAVA, utilizada para esse tipo de aplicações com excelentes resultados. Após a decisão tomada, partimos para a busca de informações e bibliografia básica sobre programação em JAVA 2D, pois era necessário conhecermos esses procedimentos antes de optarmos por um método de desenho numérico dos mitos. Como os testes com JAVA 2D foram promissores, pensamos numa possível solução para o processo de morfagem: a criação de diversas partes independentes e fechadas, que chamamos de "shapes", para comporem o desenho das criaturas. Acreditávamos que esses shapes independentes poderiam manter a integridade das diversas partes que compunham cada criatura, sem comprometer a morfagem entre elas. Além disso, a divisão em shapes poderia permitir-nos um detalhamento ainda maior do desenho, mantendo a autoralidade inicial do design dos mitos.

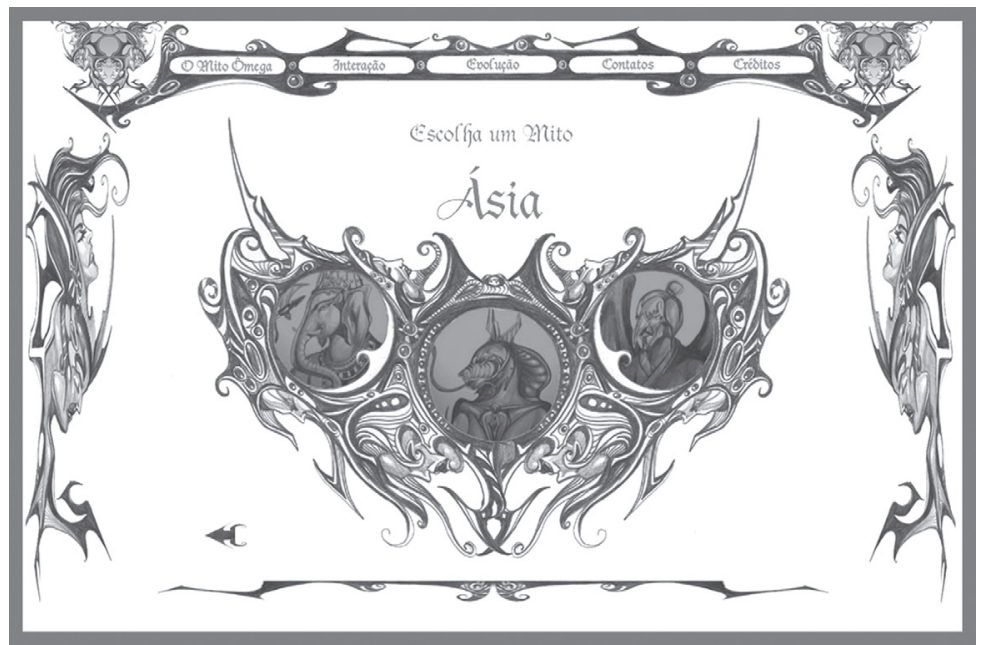

A simulação de vida em ambientes evolutivos artificiais baseados em algoritmos evolucionários tem sido usada por diversos campos da ciência, principalmente pela biologia, como o 
objetivo de simular a evolução nos sistemas naturais. Richard Dawkins, um dos principais discípulos de Charles Darwin e maior biólogo evolucionista vivo, é também programador. Ele desenvolve softwares que simulam o crescimento, reprodução e evolução das espécies, programando os princípios de seleção artificial em seus mundos artificiais. Dawkins atribui aos seus seres artificiais - todos desenhos numéricos - características regidas por "genes digitais", que podem ser: dimensões do desenho, cores, espessura dos traços, número de partes compositivas etc. Em seus programas que simulam a reprodução, esses "genes digitais" são passados para as gerações seguintes com possibilidade de mutações adaptativas. O novo design é construído a partir da interpretação do software ao analisar a mensagem desses "genes". A reprodução se repete incessantemente e a evolução vai se produzindo ao longo das gerações.

O Mito Ômega se diferencia desses experimentos, pois neles a intenção do biólogo é estritamente científica, ele tenta reforçar sua tese - defendida em livros como O Relojoeiro Cego: A Teoria da Evoluo Contra o Desgnio Divino (2001) - de que os processos naturais que levaram os organismos a evoluírem ocorrem porque em gerações sucessivas há ligeiras diferenças no desenvolvimento embrionário causado por mutações genéticas. Tais transformações não são um acaso do destino e sim um processo cumulativo de mudanças simples que vão se somando ao longo das gerações. Para Dawkins (2001:21) "Não se trata de coincidência (...) O produto final de uma geração de seleção é o ponto de partida para a próxima geração de seleção". Já o Mito Ômega é um projeto iminentemente artístico, que lança mão do ferramental da computação evolutiva, mas possui intenções de ordem estética e poética, distanciando-se do discurso lógico e racional da ciência e apoderando-se de alguns de seus princípios e do ferramental tecnocientífico para subvertê-lo, gerar ruído, produzir uma resposta ou nova pergunta artística.

A arte torna-se viva somente quando ela oferece uma estrutura teórica para questionamentos. A ciência oferece essa estrutura teórica também, mas, para mim, "a boa ciência" é por demais restritiva. Eu preferiria fazer perguntas que se endereçassem si- 
multaneamente a múltiplos mundos - dos organismos vivos até a cultura, a ferrugem e o caos. Somente a arte me dá essa generalidade. (WHITE apud SANTAELLA, 2003, p.26).

Tendo em pauta essas intenções poéticas e estéticas do trabalho, pareceu-nos interessante propor algum princípio evolutivo que subvertesse os padrões naturais e biológicos, que promovesse um aspecto inverso àquele da ordem evolutiva de nossa biosfera. Assim surgiu a idéia de subvertermos a própria aparência inicial de nossas criaturas, baseada na simetria - que por sua vez é um dado importante no processo evolutivo natural, presente nas mais diversas formas de vida terrestre - decidimos então incluir como critério de seleção natural em nosso ambiente virtual a "assimetria", além de outro critério baseado nas cores RGB, ou seja, quanto mais assimétricas e quanto mais distantes dos valores puros de red, green \& blue, mais chance de sobrevivência em nosso espaço digital. Optamos por manter sempre no ambiente de vida artificial quarenta criaturas. O número nos pareceu bom, pois para os internautas não será complicado baixar as imagens das diversas gerações que the interessarem. Já que ele poderá conferir por quantas gerações sua criatura, ou o filho de sua criatura sobreviveu no sistema, podendo baixar as imagens das diversas gerações, cada uma

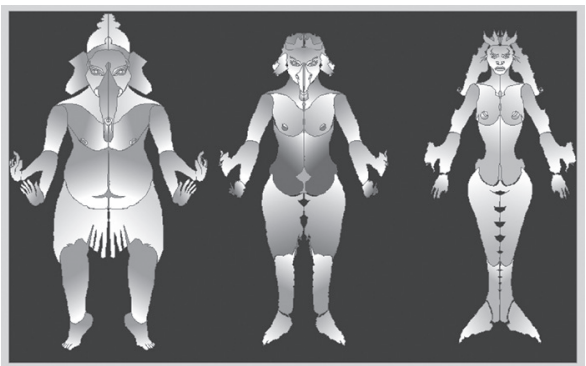

Figura 2 - Exemplos de morfagem das criaturas e criação do descendente (ao centro).

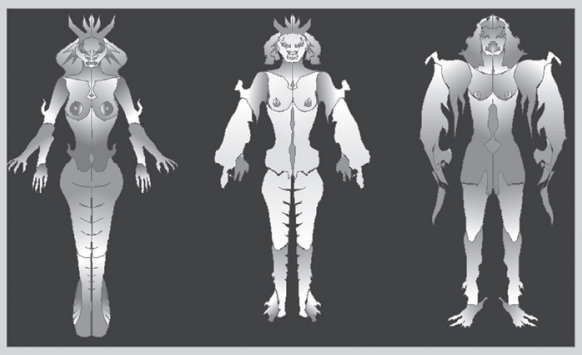


delas contará com quarenta seres.

Todo o sistema de vida artificial será retro alimentado pelos internautas, a cada entrada de um novo internauta no site as criaturas são programadas para se reproduzirem mais três vezes, assim, quanto mais visitas, mais gerações irão surgindo no ambiente de vida artificial. Isso significa que a interação se dá em dois níveis, ao selecionar e inserir o DNA digital em uma das quinze criaturas, colocando-a para reproduzir-se imediatamente e também através do "incentivo" à reprodução das demais criaturas do sistema.

Visando a disponibilização do site do projeto on-line, necessitávamos possuir no sistema as primeiras quarenta criaturas. Diante disso, decidimos gerar as outras vinte e cinco criaturas a partir da seleção aleatória de alguns dos mitos iniciais e da produção de seus "filhos". Ressaltamos novamente que em nosso processo de design evolutivo, o filho gerado por duas criaturas é sempre a média de sua forma e também de suas cores, a partir do cruzamento de dados feito no programa de morfagem.

No momento em que colocam suas criaturas para reproduzirem-se, os internautas podem visualizar o processo de nascimento do descendente, uma animação da morfagem entre as duas criaturas que vai de uma forma à outra para finalmente parar na média entre as duas criaturas. Foram feitos diversos outros testes para avaliarmos a progressão de algumas criaturas durante os processos de morfagem e a evolução das cores ao longo das gerações. Os resultados das múltiplas morfagens são surpreendentes e imprevisíveis. O projeto envolve uma série de experimentos na área de programação e gerenciamento de bancos de dados. Por tratar-se de uma pesquisa exploratória, só através de testes poderíamos saber se seria viável ou não utilizarmos uma determinada linguagem computacional. No início do projeto os bolsistas do Curso de Ciência da Computação da PUC-MG - Poços de Caldas, financiados pelo FIP Fundo de Incentivo à Pesquisa da PUC-MG, realizaram múltiplas experiências de programação para as diversas funcionalidades envolvidas no trabalho.

Atualmente estamos trabalhando na segunda fase do projeto e ela envolve uma parceria com o doutor em ciência da com- 
putação alemão Christian Rengstl da Universidade de Regensburg, ele assumiu toda a parte computacional da obra e concluímos toda a programação em Java das criaturas e do sistema que permite morfá-las. O trabalho de programação relativo à inserção do DNA metafórico nas criaturas e o banco de dados que suportará as múltiplas gerações está sendo desenvolvido gradativamente, pois a literatura sobre JAVA 2D é muito escassa, isso tem demandado um trabalho contínuo baseado em múltiplos testes com os scripts gerados.

O fruto deste trabalho está disponibilizado on-line, em uma versão beta do site - um work in progress, de caráter experimental, no endereço http://www.mitomega.com, nela já é possivel experimentar a morfagem das criaturas. Após a conclusão dessa versão beta, o trabalho passará por uma fase de avaliação on-line, e posteriormente pretendemos realizar novos experimentos evolutivos com as criaturas e desenvolver outras poéticas e aplicações para O Mito mega. No contexto contemporâneo, em que a arte tem mantido com a tecnologia e a ciência relações enriquecedoras, resultando em uma renovação do imaginário poético. O Mito Ômega é uma poética ciberartística que busca - rememorando palavras de Edmond Couchot (2003) - "substituir as certezas da ciência pelas incertezas da sensibilidade".

\section{Referências}

ASCOTT, Roy. "Quando a Onça se Deita com a Ovelha: a Arte com Mídias Úmidas e a Cultura Pós-biológica", in: Arte e Vida no Sculo XXI Tecnologia, Cincia e Criatividade (Diana Domingues org.), São Paulo: Editora Unesp, 2003, p.273-284.

BENTLEY, Peter J. Biologia Digital: Como a Natureza est transformando a Tecnologia e Nossas Vidas, São Paulo: Berkeley, 2002.

COUCHOT, Edmond. A Tecnologia Na Arte - Da Fotografia à Realidade Virtual, Porto Alegre: UFRGS Editora, 2003.

DAWKINS, Richard. O Relojoeiro Cego A Teoria da Evoluo Contra o Desgnio Divino, São Paulo: Companhia das Letras, 2001.

DOMINGUES, Diana (Org.). Arte e Vida no Século XXI - Tecnologia, Ciência e Criatividade, São Paulo: Editora Unesp, 2003.

GIANETTI, Claudia. Estética Digital - Sintopía del arte, la ciencia y la tec- 
nología, Barcelona: L’Angelot, 2002.

KURZWEIL, Ray. The Age of Spiritual Machines When Computer Exceed Human Intelligence, New York: Penguin Books, 2000.

MACHADO, Arlindo. El Paisage Meditico Sobre El desafio de Las Poticas Tecnolgicas, Buenos Aires: Livros del Rojas - Universidad Buenos Aires, 2000.

PLAZA, Julio \& TAVARES, Mônica. Processos Criativos com os Meios Eletrônicos: Poéticas Digitais, São Paulo: Hucitec, 1998.

PRADO, Gilbertto. Arte Telemática - dos intercâmbios pontuais aos ambientes virtuais multiusuário, São Paulo: Itaú Cultural, 2003.

SANTAELLA, Lucia. Culturas e Artes do Pós-Humano: Da Cultura das Mídias à Cibercultura, São Paulo: Paulus, 2003.

SOMMERER, Christa \& MIGNONNEAU, Laurent. Life Spacies - an evolutionary communication and interaction environment at ICC- NTT Museum, Tokyo - Japan, 1997.

\section{EDGAR SILVEIRA FRANCO}

Arquiteto pela UnB, mestre em multimeios pela Unicamp e doutor em artes pela ECA/USP. Autor dos livros $H Q$ e Arquitetura e HQtrnicas, sua pesquisa de doutorado, Perspectivas Ps-Humanas nas Ciberartes, foi premiada no programa Rumos 2003 do Ita Cultural SP. Além disso, é artista multimídia com trabalhos em múltiplos suportes e professor adjunto I da FAV - Faculdade de Artes Visuais da UFG - Universidade Federal de Goiás. 